\title{
PEMBERIAN ANOMALI KEDALAMAN REFLEKTIF PADA SIMULASI PERSAMAAN AIR DANGKAL DENGAN KONFIGURASI SEJAJAR
}

\author{
Nugroho Adi Pramono \\ Jurusan Fisika FMIPA Universitas Negeri Malang. \\ Jalan Semarang 5 Malang.E-mail: nugroho.adi.fmipa@um.ac.id
}

\begin{abstract}
The simulation of shallow water equation with straight configuration reflective depth anomaly has been performed. This program simulated wave absorber in the beach in order to prevent furthur abrasion of by sea. This program using modified Navier-Stokes equation and running on Matlab program. The result show that depth-anomaly reduced the amount on wave amplitudo by significant value.
\end{abstract}

Key words: Shallow Water Equation, Navier Stokes, Depth Anomaly

\section{PENDAHULUAN}

Pergerakkan gelombang air laut adalah salah satu dari proses fluida yang dapat dijelaskan melalui persamaan Navier-Stokes. Persamaan ini dapat menjelaskan bagaimana fluida mengalir. Persamaan Navier-Stokes menjelaskan 3 dimensi proses fluida dengan beberapa penyederhanaan (Thurey et al, 2006).

Penelitian ini menggunakan asumsi fluida yang dipilih adalah air dangkal (shallow water), maka pendekatannya menggunakan persamaan air dangkal. Perairan dangkal adalah perairan yang punya batas permukaan (surface) dan batas dasar (bottom) (Ancey et al, 2007). Persamaan air dangkal biasanya digunakan untuk mensimulasikan gelombang yang panjang gelombanganya mirip dengan ketinggian air secara keseluruhan (Thurey et al, 2006).

Penelitian ini telah dilakukan oleh (Ancey, 2007., Moler, 2011., Robinson, 2011., Tiwow, 2015., Thurey, dkk, 2006., Zhang, 2008) dengan membuat variabel $\mathrm{H}=1, \mathrm{u}=0$, dan $\mathrm{v}=0$. Penelitian oleh (Pramono, 2016a) dan (Pramono, 2016b) dilakukan dengan membuat variasi pada $\mathrm{H}$ di beberapa titik yang selanjutnya disebut dengan anomali. Namun pada penelitian tersebut tidak dilakukan perlakuan khusus terhadap batas anomali sehingga anomali hanya berupa sel dengan $\mathrm{H}$ tetap, sedangkan tetangganya mengikuti aturan sel normal.

Penelitian ini menambahkan syarat reflektif pada anomali sedemikian rupa sehingga sel-sel yang berbatasan dengan sel anomali akan memiliki sifat reflektif sehingga mendekati keadaan sebenarnya, yaitu gelombang air yang menabrak sebuah karang.

\section{METODE PENELITIAN}

Penelitian ini merupakan simulasi sistem fisis dengan metode komputasi. Sistem fisis yang dikaji adalah fluida dalam wadah berbentuk kubus dengan ukuran 64x64 grid dengan kedalaman satu satuan.

Pergerakan fluida dihitung dengan menggunakan persamaan air dangkal yang ditunjukkan oleh Persamaan (1), (2), dan (3).

$$
\begin{aligned}
& \frac{\partial h}{\partial !}+\frac{\partial(\mathrm{L} h)}{\partial x}+\frac{\partial^{\prime}(\mathrm{vh})}{\partial y}=0
\end{aligned}
$$

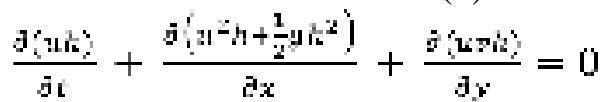




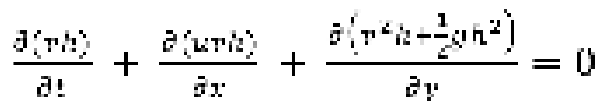

(3)

Dimana variabel bebasnya yaitu $x, y$, dan t. Untuk variabel terikatnya adalah $h$ dan dua dimensi kecepatan $u$ dan $v$. Turunan parsial diperoleh dari komponen variabel di atas $(\partial x, \partial y, \partial t)$ yang kemudian dikelompokkan menjadi vektor dan dituliskan kembali sebagai turunan hyperbolic parsial pertama

Dan Vektor nya,

$$
\begin{gathered}
U=\left(\begin{array}{c}
h \\
u h \\
v h
\end{array}\right) \\
F(U)=\left(\begin{array}{c}
u h \\
u^{2} h+\frac{1}{2} g h^{2} \\
u v h
\end{array}\right) \\
G(U)=\left(\begin{array}{c}
v h \\
u v h \\
v^{2} h+\frac{1}{2} g h^{2}
\end{array}\right)
\end{gathered}
$$

Persamaan turunan hyperbolic parsial pertama :

$$
\frac{\partial U}{\partial t}+\frac{\partial F(U)}{\partial x}+\frac{\partial G(U)}{\partial y}=0
$$

Gambar 1a merupakan grid dari sistem fisis yang ditinjau, setiap sel memiliki $u, v$ dan $h$ dengan nilai awal nol untuk $\mathrm{u}$ dan $\mathrm{v}$ dan 1 untuk h. Saat sistem diberi gangguan, maka nilai dari $\mathrm{u}, \mathrm{v}$ dan $\mathrm{h}$ tiap sel akan berubah sesuai dengan persamaan (7).

Penyelesaian dari persamaan turunan parsial hiperbolik adalah dengan metode numerik, yaitu dengan menggunakan metode Lax-Wendroff. Dalam metode ini, untuk mendapatkan nilai $\mathrm{u}, \mathrm{v}$ dan $\mathrm{h}$ pada $\mathrm{t}+1$, kita harus mencari nilai antara seperti yang ditampilkan di Gambar 2. Nilai antara titik-titik tersebut dicari dengan menggunakan persamaan (8) dan (9)

$$
\begin{aligned}
& U_{i+\frac{1}{2}, j}^{n+\frac{1}{2}}=\frac{1}{2}\left(U_{i+1, j}^{n}+U_{i, j}^{n}\right)-\frac{\Delta t}{2 \Delta x}\left(F_{i+1, j}^{n}-F_{i, j}^{n}\right) \\
& U_{i, j+\frac{1}{2}}^{n+\frac{1}{2}}=\frac{1}{2}\left(U_{i, j+1}^{n}+U_{i, j}^{n}\right)-\frac{\Delta t}{2 \Delta y}\left(G_{i, j+1}^{n}-G_{i, j}^{n}\right)
\end{aligned}
$$



Gambar 1. a) grid dari sitem fisis, b) nilai antara untuk menghitung $\mathrm{u}, \mathrm{v}$, dan $\mathrm{h}$ di $\mathrm{t}+1$.

Dari nilai-nilai antara tersebut kita dapat menghitung nilai di $\mathrm{t}+1$ dengan persamaan (10)

$$
U_{i, j}^{n+1}=U_{i, j}^{n}-\frac{\Delta t}{\Delta x}\left(F_{i+\frac{1}{2}, j}^{n+\frac{1}{2}}-F_{i-\frac{1}{2}, j}^{n+\frac{1}{2}}\right)-\frac{\Delta t}{\Delta y}\left(G_{i, j+\frac{1}{2}}^{n+\frac{1}{2}}-G_{i, j-\frac{1}{2}}^{n+\frac{1}{2}}\right)
$$


Berikut merupakan bagan alur program

reflektif. simulasi persamaan air dangkal dengan syarat

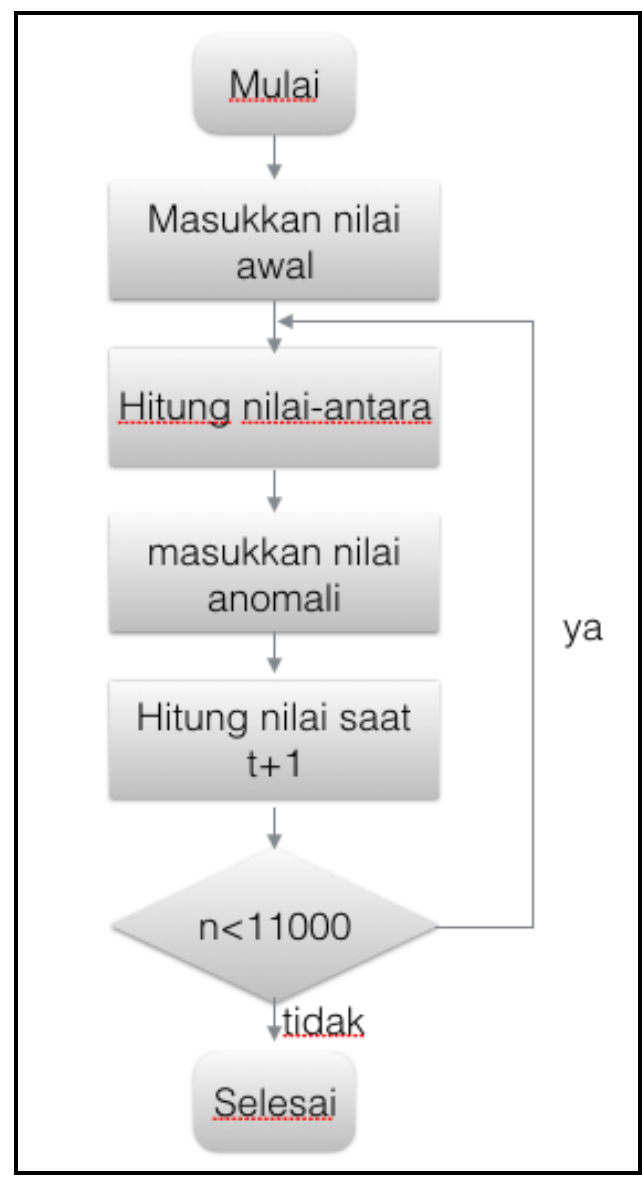

Di Matlab, dibuat matrik yang mewakili sistem fisis dan diberi nilai awal dengan kode sebagai berikut

$\mathrm{H}=$ ones $(\mathrm{n}+2, \mathrm{n}+2) ; \quad \mathrm{U}=\operatorname{zeros}(\mathrm{n}+2, \mathrm{n}+2) ; \mathrm{V}=$ zeros $(n+2, n+2)$;

$\mathrm{Hx}=\operatorname{zeros}(\mathrm{n}+1, \mathrm{n}+1) ; \mathrm{Ux}=\operatorname{zeros}(\mathrm{n}+1, \mathrm{n}+1) ; \mathrm{Vx}$ $=\operatorname{zeros}(\mathrm{n}+1, \mathrm{n}+1)$;

$\mathrm{Hy}=\operatorname{zeros}(\mathrm{n}+1, \mathrm{n}+1) ; \mathrm{Uy}=\operatorname{zeros}(\mathrm{n}+1, \mathrm{n}+1) ; \mathrm{Vy}$

$=\operatorname{zeros}(\mathrm{n}+1, \mathrm{n}+1)$;

Untuk menyimpan data sel[1,1] selama program berjalan, digunakan perintah berikut data=nstep;
dlmwrite('SB3nStepR.csv',data,'delimiter',,','append'); data $=\mathrm{H}(1,1)$;

dlmwrite('SB3HR.csv',data,'delimiter,',','append');

Syarat reflektif tepi sistem

$$
\mathrm{H}(:, 1)=\mathrm{H}(:, 2) ; \quad \mathrm{U}(:, 1)=\mathrm{U}(:, 2) ;
$$

$\mathrm{V}(:, 1)=-\mathrm{V}(:, 2)$;

$\mathrm{H}(:, \mathrm{n}+2)=\mathrm{H}(:, \mathrm{n}+1) ; \mathrm{U}(:, \mathrm{n}+2)=\mathrm{U}(:, \mathrm{n}+1) ;$

$\mathrm{V}(:, \mathrm{n}+2)=-\mathrm{V}(:, \mathrm{n}+1)$;

$\mathrm{H}(1,:)=\mathrm{H}(2,:) ; \quad \mathrm{U}(1,:)=-\mathrm{U}(2,:) ;$

$\mathrm{V}(1,:)=\mathrm{V}(2,:)$;

$H(n+2,:)=H(n+1,:) ; \quad U(n+2,:)=-U(n+1,:) ;$ 
$\mathrm{V}(\mathrm{n}+2,:)=\mathrm{V}(\mathrm{n}+1,:) ;$

Setengah langkah pertama adalah menghitung nilai-antara pada Persamaan (8) sebagai berikut

$$
\mathrm{i}=1: \mathrm{n}+1 ; \mathrm{j}=1: \mathrm{n} \text {; }
$$

$$
\mathrm{Hx}(\mathrm{i}, \mathrm{j})=(\mathrm{H}(\mathrm{i}+1, \mathrm{j}+1)+\mathrm{H}(\mathrm{i}, \mathrm{j}+1)) / 2-
$$

$\mathrm{dt} /(2 * \mathrm{dx}) *(\mathrm{U}(\mathrm{i}+1, \mathrm{j}+1)-\mathrm{U}(\mathrm{i}, \mathrm{j}+1))$;

$$
\mathrm{Ux}(\mathrm{i}, \mathrm{j})=(\mathrm{U}(\mathrm{i}+1, \mathrm{j}+1)+\mathrm{U}(\mathrm{i}, \mathrm{j}+1)) / 2-\ldots
$$
$\mathrm{dt} /\left(2^{*} \mathrm{dx}\right)^{*}\left(\left(\mathrm{U}(\mathrm{i}+1, \mathrm{j}+1) .^{\wedge} 2 . / \mathrm{H}(\mathrm{i}+1, \mathrm{j}+1)+\right.\right.$ $\left.\mathrm{g} / 2 * \mathrm{H}(\mathrm{i}+1, \mathrm{j}+1))^{\wedge} 2\right)-\ldots$

$$
\begin{aligned}
& (\mathrm{U}(\mathrm{i}, \mathrm{j}+1))^{\wedge} 2 . / \mathrm{H}(\mathrm{i}, \mathrm{j}+1)+ \\
& \left.\left.\mathrm{g} / 2^{*} \mathrm{H}(\mathrm{i}, \mathrm{j}+1) .^{\wedge} 2\right)\right) \\
& \mathrm{Vx}(\mathrm{i}, \mathrm{j})=(\mathrm{V}(\mathrm{i}+1, \mathrm{j}+1)+\mathrm{V}(\mathrm{i}, \mathrm{j}+1)) / 2-\ldots \\
& \mathrm{dt} /(2 * \mathrm{dx}) *((\mathrm{U}(\mathrm{i}+1, \mathrm{j}+1) \cdot * \mathrm{~V}(\mathrm{i}+1, \mathrm{j}+1) . / \mathrm{H}(\mathrm{i}+1, \mathrm{j}+1) \\
& \text { ) }- \text {... } \\
& (\mathrm{U}(\mathrm{i}, \mathrm{j}+1) * \mathrm{~V}(\mathrm{i}, \mathrm{j}+1) \cdot / \mathrm{H}(\mathrm{i}, \mathrm{j}+1))) \text {; }
\end{aligned}
$$$$
\text { dan Persamaan (9) sebegai berikut } \mathrm{i}=
$$
$1: n ; j=1: n+1$;

$$
\mathrm{Hy}(\mathrm{i}, \mathrm{j})=(\mathrm{H}(\mathrm{i}+1, \mathrm{j}+1)+\mathrm{H}(\mathrm{i}+1, \mathrm{j})) / 2-
$$

$\mathrm{dt} /(2 * \mathrm{dy}) *(\mathrm{~V}(\mathrm{i}+1, \mathrm{j}+1)-\mathrm{V}(\mathrm{i}+1, \mathrm{j}))$;

$$
\mathrm{Uy}(\mathrm{i}, \mathrm{j})=(\mathrm{U}(\mathrm{i}+1, \mathrm{j}+1)+\mathrm{U}(\mathrm{i}+1, \mathrm{j})) / 2-\ldots
$$

$\mathrm{dt} /(2 * \mathrm{dy}) *\left(\left(\mathrm{~V}(\mathrm{i}+1, \mathrm{j}+1) \cdot{ }^{*} \mathrm{U}(\mathrm{i}+1, \mathrm{j}+1) . / \mathrm{H}(\mathrm{i}+1, \mathrm{j}+1)\right.\right.$ ) - ...

$(\mathrm{V}(\mathrm{i}+1, \mathrm{j}) . * \mathrm{U}(\mathrm{i}+1, \mathrm{j}) . / \mathrm{H}(\mathrm{i}+1, \mathrm{j})))$;

$\mathrm{Vy}(\mathrm{i}, \mathrm{j})=(\mathrm{V}(\mathrm{i}+1, \mathrm{j}+1)+\mathrm{V}(\mathrm{i}+1, \mathrm{j})) / 2-\ldots$ $\mathrm{dt} /(2 * \mathrm{dy}) *\left(\left(\mathrm{~V}(\mathrm{i}+1, \mathrm{j}+1) .^{\wedge} 2 . / \mathrm{H}(\mathrm{i}+1, \mathrm{j}+1)+\right.\right.$ $\left.\mathrm{g} / 2^{*} \mathrm{H}(\mathrm{i}+1, \mathrm{j}+1) .^{\wedge} 2\right)-\ldots$ $\left.\left.\mathrm{g} / 2 * \mathrm{H}(\mathrm{i}+1, \mathrm{j}) \wedge^{\wedge} 2\right)\right)$

$$
\left(\mathrm{V}(\mathrm{i}+1, \mathrm{j}) .^{\wedge} 2 \cdot / \mathrm{H}(\mathrm{i}+1, \mathrm{j})+\right.
$$

Setengah langkah kedua adalah menghitung nilai di $t+1$ seperti pada Persamaan (10)

$\mathrm{i}=2: \mathrm{n}+1$;

$\mathrm{j}=2: \mathrm{n}+1$;

$H(i, j)=H(i, j)-(d t / d x) *(U x(i, j-1)-U x(i-1, j-1))-$ $(\mathrm{dt} / \mathrm{dy}) *(\mathrm{Vy}(\mathrm{i}-1, \mathrm{j})-\mathrm{Vy}(\mathrm{i}-1, \mathrm{j}-1))$

$\mathrm{U}(\mathrm{i}, \mathrm{j})=\mathrm{U}(\mathrm{i}, \mathrm{j})-(\mathrm{dt} / \mathrm{dx}) *\left(\left(\mathrm{Ux}(\mathrm{i}, \mathrm{j}-1) .^{\wedge} 2 . / \mathrm{Hx}(\mathrm{i}, \mathrm{j}-\right.\right.$ 1) $+\mathrm{g} / 2 * \mathrm{Hx}(\mathrm{i}, \mathrm{j}-1) . \wedge 2)-\ldots$

$\left(\mathrm{Ux}(\mathrm{i}-1, \mathrm{j}-1) .^{\wedge} 2 . / \mathrm{Hx}(\mathrm{i}-1, \mathrm{j}-1)+\mathrm{g} / 2 * \mathrm{Hx}(\mathrm{i}-1, \mathrm{j}-\right.$ 1).^2)) ...

$1, \mathrm{j}) . / \mathrm{Hy}(\mathrm{i}-1, \mathrm{j}))-\ldots$

$$
-(\mathrm{dt} / \mathrm{dy}) *((\mathrm{Vy}(\mathrm{i}-1, \mathrm{j}) . * \mathrm{Uy}(\mathrm{i}-
$$

$(\mathrm{Vy}(\mathrm{i}-1, \mathrm{j}-1) . * \mathrm{Uy}(\mathrm{i}-1, \mathrm{j}-1) \cdot / \mathrm{Hy}(\mathrm{i}-$

$1, \mathrm{j}-1)))$;

$\mathrm{V}(\mathrm{i}, \mathrm{j})=\mathrm{V}(\mathrm{i}, \mathrm{j})-(\mathrm{dt} / \mathrm{dx}) *\left(\left(\mathrm{Ux}(\mathrm{i}, \mathrm{j}-1) \cdot{ }^{*} \mathrm{Vx}(\mathrm{i}, \mathrm{j}-\right.\right.$

1)./Hx(i,j-1)) - ...

$1, \mathrm{j}-1))) \ldots$

$\left(\mathrm{Ux}(\mathrm{i}-1, \mathrm{j}-1) \cdot{ }^{*} \mathrm{Vx}(\mathrm{i}-1, \mathrm{j}-1) \cdot / \mathrm{Hx}(\mathrm{i}-\right.$ $-(\mathrm{dt} / \mathrm{dy}) *\left(\left(\mathrm{Vy}(\mathrm{i}-1, \mathrm{j}) .^{\wedge} 2 . / \mathrm{Hy}(\mathrm{i}-1, \mathrm{j})+\right.\right.$ $\left.\mathrm{g} / 2 * \mathrm{Hy}(\mathrm{i}-1, \mathrm{j}) .^{\wedge} 2\right)-\ldots$

$$
\left(\mathrm{Vy}(\mathrm{i}-1, \mathrm{j}-1) \cdot^{\wedge} 2 . / \mathrm{Hy}(\mathrm{i}-1, \mathrm{j}-1)+\right.
$$

$\left.\left.\mathrm{g} / 2 * \mathrm{Hy}(\mathrm{i}-1, \mathrm{j}-1) .^{\wedge} 2\right)\right)$

Untuk anomali berselang non-reflektif digunakan kode seperti berikut for $\mathrm{i}=1: \mathrm{n}$

if $\bmod (\mathrm{i}, 4)==0$

$$
\mathrm{H}(\mathrm{i}, 20)=1 \text {; }
$$

end

end

Untuk anomali berselang reflektif gunakan kode

$$
\text { for } i=1: n
$$

if $\bmod (\mathrm{i}, 4)==0$

$$
\mathrm{H}(\mathrm{i}, 20)=1 \text {; }
$$

$\mathrm{H}(\mathrm{i}, 21)=\mathrm{H}(\mathrm{i}, 22)$;

$\mathrm{H}(\mathrm{i}, 19)=\mathrm{H}(\mathrm{i}, 18)$;

end

end

Ketiga program simulasi, baik normal, menggunakan anomali non reflektif, maupun reflektif dijalankan dalam loop hingga 11000 loop.

Untuk membandingkan pengaruh anomali antara variasi selang, nilai amplitudo gelombang di sel $[1,1]$ dicatat selama program berjalan. Hasil yang dibandingkan adalah grafik $\mathrm{H}$ terhadap $\mathrm{t}$ pada sel $[1,1]$ pada simulasi persamaan air dangkal normal (tanpa anomali kedalaman), simulasi dengan anomali sejajar (non-reflektif), dan simulasi dengan anomali sejajar reflektif. 


\section{HASIL DAN PEMBAHASAN}

Hasil simulasi secara visual $3 \mathrm{~d}$ dapat dilihat pada Gambar 2. Gambar 3b menunjukkan amplitudo sel yang sama saat sistem diberi anomali kedalaman reflektif. Dari grafik terlihat bahwa seiring berjalannya waktu, amplitudo sel menjadi relatif lebih kecil daripada sistem fisis dengan anomali reflektif. Perbandingan amplitudo sel[1,1] saat pemberian anomali reflektif dan non reflektif dapat di lihat pada Gambar 3c. Gambar 3d menunjukkan perbandingan amplitudo yang sama dengan $3 \mathrm{c}$, namun kali ini dengan menambahkan grafik amplitudo simulasi normal tanpa pemberian anomali kedalaman.

Dapat dilihat bahwa di setiap saat, grafik amplitudo sel[1,1] pada simulasi tanpa anomali (warna merah) selalu lebih tinggi daripada grafik simulasi dengan anomali. Pemberian syarat reflektif pada sel yang berbatasan langsung dengan anomali menjadikan amplitudo sel[1,1] lebih kecil dibandingkan dengan simulasi dengan anomali non-reflektif.

Grafik amplitudo sel [1,1] selama program berjalan untuk sistem dengan anomali non reflektif dapat dilihat pada Gambar 3.a.

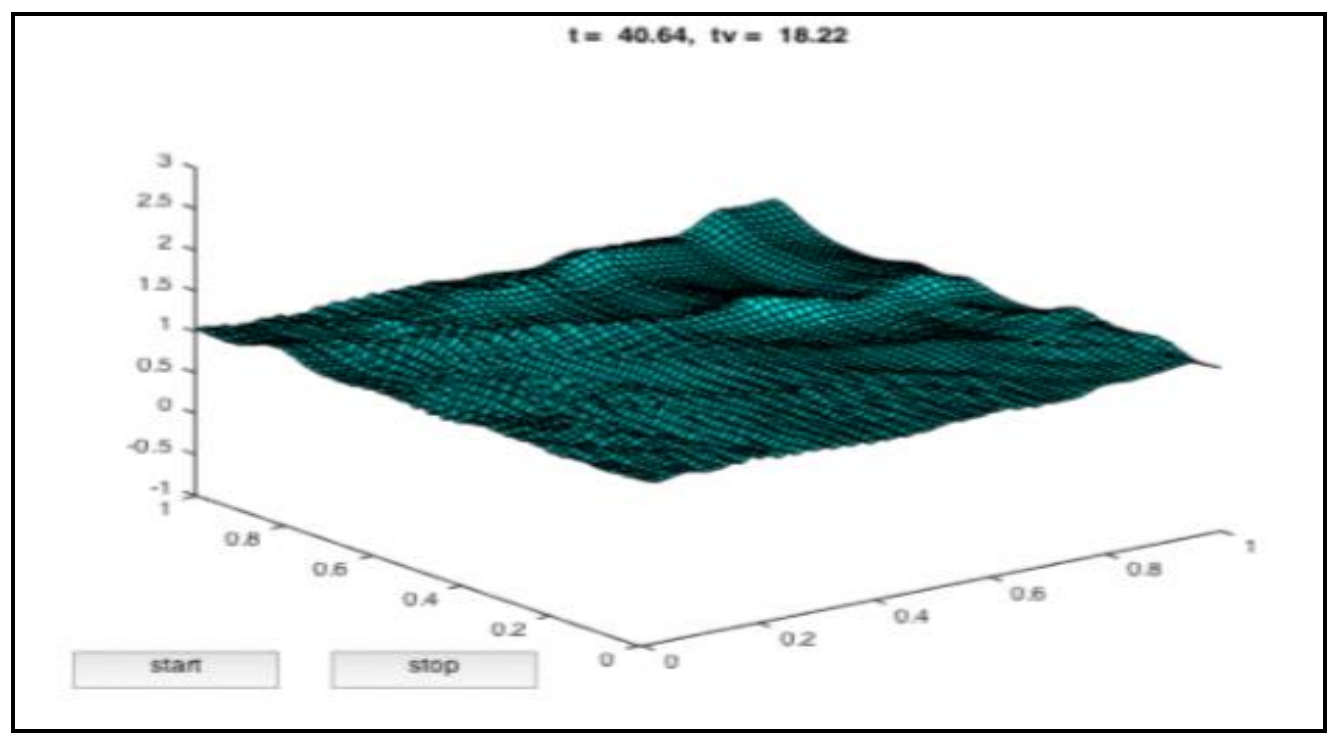

Gambar 2. Hasil simulasi 3D

\section{KESIMPULAN}

Hasil simulasi menunjukkan bahwa pemberian anomali kedalaman dapat mengubah arah gelombang dan menurunkan amplitudo gelombang. Pemberian anomali sejajar-denganselang memiliki hasil yang tidak begitu berbeda pada variasi jarak antar anomali. Jarak antara anomali kedalaman menentukan muka gelombang yang melalui konfigurasi anomali yang berfungsi sebagai celah sempit. Perlu dilakukan penelitian lebih lanjut dengan memperlakukan sel yang berbatasan langsung dengan anomali kedalaman dengan perlakuan lebih menyeluruh, misal dengan membuat syarat reflektif berlaku tidak hanya untuk kedalaman melainkan kecepatan arah-x dan y sel yang berbatasan langsung dengan anomali tersebut. 


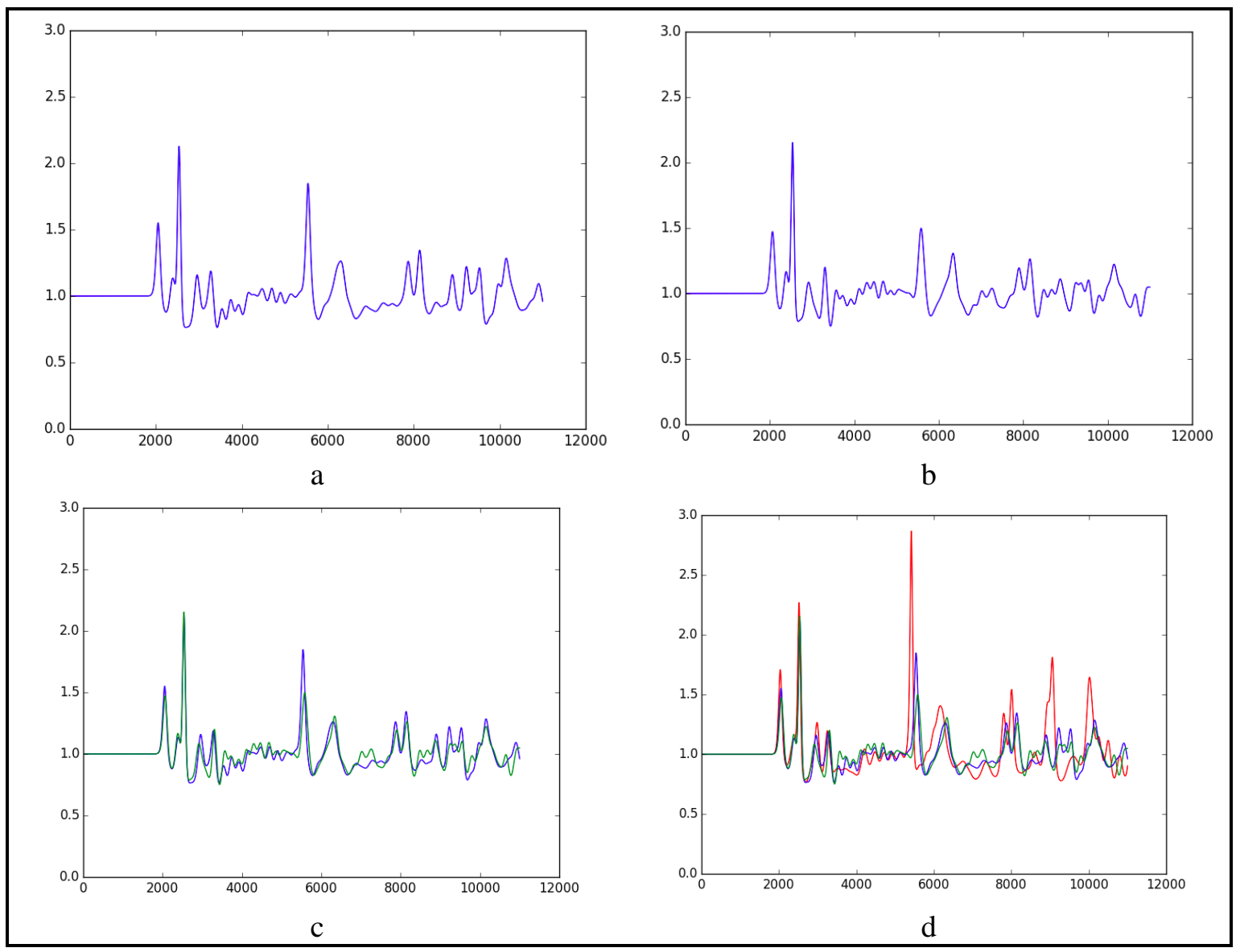

Gambar 3. Amplitudo sel [1,1] pada a) anomali sejajar berselang, b) anomali sejajar berselang reflektif, c) gabungan nilai amplitudo non-reflektif (warna biru) dan reflektif (warna hijau), d) gabungan nilai amplitudo simulasi normal, berselang dan berselang reflektif (warna hijau adalah amplitudo simulasi tanpa anomali).

\section{DAFTAR KEPUSTAKAAN}

Ancey C. 2007. Plasticity and Geophysical Flows.. Journal of Non-Newtonian Fluid Mechanics (4-35). Lausanne, Switzerland: Ecole Polytechnique Federale de Lausanne

Aref H. 2012. The Navier-Stokes equation : a Classification of Flows and Exact Solution. Theory Computation Fluid Dynamic (26:481). Cambridge University.

Erratum. 2000. On the Derivation of the Buckley-Leverett Model from the Two Fluid Navier-Stokes Equation in a Thin
Domain Computational Geoscience. Computational Geoscience (99-101). France : UFR Matemathique, Analyse Numerique.

Hinkelmann R, Liang Q, Aizinger V, Dawson C. 2015. Robust Shallow Water Model. Environ Earth Science,(74:7273-7274).

LeVeque RJ. 2005. Finite Difference Methods for Differential Equation. AMath (585586). Washington : University Of Washington.

Moler C. Chapter 18: Shallow Water Equations. Experiments with MATLAB. MathWorks. Web. 
<http://www.mathworks.com/moler/exm/ chapters.html>.

Pramono NA. 2016a. Pemberian Anomali Kedalaman Reflektif pada Simulasi Persamaan Air Dangkal dengan Konfigurasi Sejajar. Prosiding Seminar Nasional Fisika Universitas Negeri Malang, Seminar Nasional Fisika dan Pembelajarannya. Malang: 6 Agustus 2016.

Pramono NA. 2016b. Simulasi Persamaan Air Dangkal Menggunakan Persamaan Navier-Stokes Dengan Penambahan Anomali Kedalaman Konfigurasi ZigZag Sebagai Pemecah Ombak. Prosiding Seminar Nasional Fisika Universitas Negeri Malang, Seminar Nasional Fisika dan Pembelajarannya. Malang: 6 Agustus 2016.

Robinson CR. 2011. Shallow Water Equation. Syracuse University.

Setiawan T. 2015. Fluida Dinamis.
Stubbe P. 2015. The Euler and Navier-Stokes Equation Revisited. Physics Fluids Dynamic.

Suhamjani J. 2005. Aplikasi Lagrangian Navier-Stokes pada Turbulensi. Bogor : Intitut Pertanian Bogor.

Thurey N, Muller-Fischer M, Schrim S, Gross M. 2006. Real-time Breaking Waves for Shallow Water Simulation. Switzerland : ETH Zurich, AGEIA Technologies.

Tiwow VA, Malago JD. 2015. Application of Navier-Stokes Equation to Laminar Fluid Flow Case in Unhorizontal Pipe. Jurnal Sainsmat (51-56). Makassar:FMIPA Universitas Negeri Makassar.

Tubbs K. 2010. Lattice Boltzmann Modelling for Shallow Water Equation Using High Performance Computing.

Zhang H, Shi Y, Yuen DA, Yan Z, Yuan X dan Zhang C. 2008. Modelling and Visualization of Tsunamis. Pure and Applied Geophysics,(475-496). 